•论坛・ 中国国家公园试点专题

\title{
我国国家公园人类活动特征、管理问题与调整策略
}

彭奎 ${ }^{*}$

永续全球环境研究所, 北京 100086

彭奎 (2021) 我国国家公园人类活动特征、管理问题与调整策略. 生物多样性, 29, 278-282. doi: 10.17520/biods.2021065.

Peng K (2021) Basic characteristics, management problems and adjusted strategies of human activities for China’s national parks. Biodiversity Science, 29, 278-282. doi: 10.17520/biods.2021065.

\section{Basic characteristics, management problems and adjusted strategies of human activities for China's national parks}

Kui Peng*

Global Environmental Institute, Beijing 100086

在现代自然保护与经济开发的历史关系中, 人 类活动总是处于关键角色和矛盾焦点。早期将人 隔离在自然系统之外的堡垒保护 (fortress conservation)逐步被更加包容的保护所替代, 尤其 是纳入地方社区在生物多样性保护中的角色和作 用 (Berkes, 2007; Garnett et al, 2018; Rai et al, 2021)。管理保护地人类活动并实现可持续发展, 成 为全球自然保护共同面临的最大挑战。我国国家 公园的首要功能是重要自然生态系统的原真性、 完整性保护, 但同时强调要兼具科研、教育、游㓤 等综合功能, 这必然涉及到监测保护、科研教育、 游悡体验和社区发展等多样化的人类活动。把握 我国国家公园人类活动特征, 平衡人类活动的范 围、方式和强度, 是实现国家公园“全民共享、世 代传承”的重大任务。本文从试点国家公园人类活 动主要特征出发, 探讨我国试点国家公园重要人类 活动的管理和存在问题, 并提出相应调整策略, 以 期为国家公园的制度设计及建设实践提供参考。

\section{我国试点国家公园人类活动基本特征}

在长期农牧生产生活和快速经济发展的双重 作用下, 我国国家公园内的人类活动十分复杂。根 据人类活动的主体, 笔者将其简化为三大类型: 社 区活动、管理活动和外部访客活动。概括而言, 我
国国家公园人类活动有以下几个鲜明共性:

(1)社区人口密度较高且总量大, 人类活动分 散。我国国家公园保护范围大, 永久性居民较多。 除了青藏高原的两个试点区人口密度较低之外, 其 余 8 个国家公园人口密度较大(指国家公园涉及社区 的户籍人口数, 不包括非常住人口数), 尤其是东部, 均远超加拿大和澳大利亚的平均人口密度。大量 分散的社区人为活动使国家公园的保护及管理面 临巨大压力。再加上国家公园区域较为偏远, 经济 相对落后, 因而社区的经济发展又必须成为国家公 园建设的主要目标之一。

(2)生产生活空间与保护空间交错重叠, 人类活 动对自然资源的依赖程度高。我国国家公园试点 均以自然保护地为基础, 同当地居民的村落、农 田、牧场以及集体山林等生产和生活空间有大量 交错重叠(徐网谷等, 2016), 人类活动的自然资源依 赖程度强, 多数产业以传统的小农种植或牧业为主 且会长期存在。三江源和祁连山传统草原牧业、 武夷山的茶叶种植、东北虎豹的林副业、钱江源 的果园茶园等, 部分深入分散在核心区内; 一些国 家公园的传统旅游产业也利用园区内的核心景观, 这与国外国家公园的建设基础有很大差异(高燕等, 2017)。

(3)基层生态保护和监管执法活动主要依靠地 
方行政系统和原住民开展。基层管理和巡护体系 很大程度上依赖地方政府职能部门; 基层巡护执法 人员来自公园及其毗邻区原住民, 而不是建立一个 独立或垂直的管理和巡护员(ranger)体系, 这充分考 虑了我国的国情, 但执法体系需要更多地处理并协 调与地方的关系(喊振华等, 2020)。如武夷山基层 管理站站长由所在地乡(镇)长兼任; 三江源国家公 园生态管护公益岗位“一户一岗”全覆盖, 并组建了 乡镇管护站、村级管护队和管护小分队; 多数试点 将专业岗位与转产脱贫挂钩, 承担了双重任务。

(4)访客活动以普通观光旅游为主, 自然体验和 环境教育刚刚起步。各试点均是依托自然保护 区、森林公园、地质公园、风景名胜区等整合而 成, 有的原本就是著名的观光旅游胜地, 如普达 措、神农架、武夷山等, 以接待普通观光旅游为目 的曾进行过较大规模的设施建设, 与国家公园以自 然保护、自然体验和教育为主要目的的公益性服 务不完全一致。仅有三江源等少数试点在小范围 内开展自然体验探索; 国内试点的国家公园环境教 育也仅是针对学校学生的宣传式教育。

\section{2 我国国家公园人类活动管理及主要问题}

结合我国国家公园的人类活动特点, 各试点开 展了一些针对性的管理改革和实践, 但仍面临一些 关键问题和挑战。

(1)科学规划并制定地方政策来规范行为, 但制 度设计的统一性不足。各试点通过国家公园总体 规划、专项规划、管理条例和其他专项管理办法 来规范管理社区居民、访客和运营等特殊人为活 动。但由于缺少中央层面对各方面制度设计的统 一要求和指导细则, 各地对自然体验、社区安排等 管理的设计宽严尺度各异, 更多强调地方的特殊性, 甚至同一试点不同片区会出台不同的管理办法, 如 国家公园各不相同的设施标准; 改革出现“国家公 园地方化” 倾向, 有的已偏离了国家公园全民共享 的宗旨。个别地方沿用景区传统经营模式, 将旅游 和体验服务项目整体打包给相关企业长期经营, 与 公益目标的特许经营本质产生了一定偏离。

(2)用管控分区划分人类活动范围和类型, 规划 粗放, 操作难度大。试点实行差别化的分区管控, 将自然保护区“三区法”统一调整为核心保护区和一
般控制区的“两区法”, 有利于保持自然系统的完整 性。但两区法沿用了简单的大块分区思路, 核心区 占比大且连片, 未能充分考虑我国国家公园人类活 动历史和功能需要。这一方面使所有的核心保护 区内都仍然存在交通道路、景点、牧场和农田等, “禁止人为活动”仍无法真正落地; 另一方面使核心 区重要景观资源成为严格保护的对象, 如黄河源的 两湖与牛头碑、普达措的碧塔海、祁连山的岗什 卡雪峰等, 试点不得不暂停或禁止在这些区域开展 任何活动, 使国家公园包括自然体验和环境教育的 “全民共享”失去了重要载体。

(3)采用移民方式降低人类活动强度, 但弱化了 本土传统知识和文化的作用。各试点通过生态移 民减少以至消除核心区人口, 以达到降低人为活动 的要求。我国国家公园内自然与农牧生产形成了 许多相对平衡的耦合系统, 某些区域禁止人为活动 不但难以实现更好的保护, 反而会对一些生态系统 和物种产生负面影响。比如高原传统游牧有利于 保持草原生态系统的健康( $\mathrm{Li}, 2017)$, 秦岭传统的稻 田耕作使朱噮(Nipponia nippon)等珍稀鸟类获得稳 定食物(Berkes, 2007), 一些传统知识和文化与自然 相融(如藏区圣境文化), 往往是其丰富的生物多样 性得以保存至今的原因(彭奎, 2020a)。试图消除这 些人为活动而制造“无人区”, 可能会同时弱化和消 除社区生态智慧、价值观和能力, 并打破由此产生 的人与自然系统平衡态, 使保护事倍功半。

(4)严格控制外部访客, 国民体验和服务形式 化。各地均重点实施严格生态保护, 而为全社会提 供科研、教育、体验、游㮩等“公共服务”涉及较 少。地方直于公共服务利益牵扯多、改革难度 大、风险高而严控访客, 将建设访客中心、科普馆 等硬件设施作为任务和成果, 而支撑全民体验活动 所必需的线路营地系统、课程体系、标识和解说 系统、服务人才、访客管理监测评估等软环境建 设十分缺乏。许多重要景点均处于关闭或半关闭 状态, 地方经济也受到较大影响, 一定程度上动摇 了国家公园在国民心目中的认同感。

(5)强化政府主导管理, 社区及社会资源未能得 到较好动员。国家公园是全民公益事业, 在坚持由 国家确立并主导管理前提下, 需要全社会参与共建 才能取得成功。但各试点强化了政府的主导地位, 
管理仍依赖单一行政力量, 社区、企业、民间机构 和公众等社会力量很少参与管理运行活动。作为 重要利益相关者的社区多扮演被动服务角色, 而未 在制度上明确社区参与管理、协商、决策和监督 的权责利(何思源, 2020); 没有建立具中国国家公园 统一形象品牌的志愿者服务及配套体系, 使公众缺 少服务国家公园的热情; 缺少民间机构和企业参与 国家公园保护管理的保障激励机制, 难以调动多渠 道、市场化的专业力量和强大的资源动员能力。

\section{3 改进国家公园人类活动管理策略的建议}

\section{1 强化国家公园人类活动管理的一致性}

国家公园的首要目标是要建成统一规范高效 的中国特色国家公园体制, 无论是中央直接管理, 还是委托管理, 都要求全国的国家公园在体制、规 范、标准、资金和评估等基本规则上保持一致，使 国家公园建设坚持“国家所有” (国有而非地方财 产)、“全民共享” (国民公共利益而非地方牟利)和 “国家主导” (国家确立并主导管理)的正确方向。因 此, 首先需要在有关社区活动、访客活动和运营活 动等人类活动管理方面, 强化全国一致的精神理 念、指导原则、主体框架、核心内容和基础标准 等, 使人类活动不会损害我国国家公园生态保护第 一的目标; 其次, 总结试点和国际经验教训, 在游㕷 体验、自然教育、特许经营、社会参与、志愿者 服务、标识和品牌系统等方面, 国家公园管理局出 台统一的制度建设指南, 作为试点国家公园完善制 度和新国家公园设立的基本要求, 从而避免国家公 园“地方化”和“逐利化”, 体现国家利益, 彰显国家形 象, 取得国民高度认同。

\section{2 科学调整并细化国家公园管控分区}

首先, 调整国家公园管控分区, 为人类活动划 定合理的边界。对国家公园“两区”范围进行更科学 细致的研究, 以保证生态系统及生态过程完整性为 前提，建议将被划入核心区的、不会影响保护目标 的、且会长期存在的已有交通道路、自然村落、 基础设施以及能为公众提供良好环境教育和自然 体验的非敏感性景观资源调整为一般控制区。使 环境教育和生态体验线路与核心保护区有机镶嵌 而非截然分离, 促进公众能够亲近并了解国家公园 壮美的自然与文化, 也使社区传统智慧继续发挥作
用, 同时满足原住民和访客的福祉。

其次, 对人类活动实施精细化管理, 对“两区”实 施更科学的功能分区, 规范人类活动类型及强度, 并分别制定严格的监测监管措施。在核心保护区, 可以分为严格保育区 $($ 禁止除保护所需的监测巡护 之外的所有人为活动)、生态保育修复区(可以开展 批准的以自然修复为主的生态修复及科学研究活 动)、传统协同保育区(允许保留有利于促进生态保 护的传统生产生活方式及生态文化活动)等功能区; 在一般控制区, 可以分为传统生产生活区(在环境容 量之下的传统的生态友好型生产生活区)、人工生 态修复区 (需要工程措施进行生态修复和廊道建设 的区域)、大众游喤体验区(普通公众体验自然的环 境教育场所和开展相关生态旅游等活动的区域)、 特殊生态体验区(提供更深度和小众的徒步、科考 探险、文化和自然游学等的线路产品, 满足多层次 需求, 严格控制人数)。

基于管控分区和功能分区，结合现代科技实施 差别化精细化管理，是符合我国国情的国家公园管 理的必然要求。

\section{3 明确原住民社区继续存在的形式和权利}

社区能否成为国家公园建设的主要参与者并 获得可持续发展, 是我国国家公园改革能否成功的 核心标志之一(彭奎, 2020b)。建议: (1)建立健全国 家公园内及周边原住民社区存续的相关制度，明确 在国家公园核心区和一般控制区以及各功能区中 各原住民社区的功能定位、规模、位置、边界，以 此规范和引导社区的人口发展、基础建设和生产 生活边界; (2)认可原住民传统智慧对生态保护的地 位和作用，通过科学评估和共同协商，用制度和规 范确立原住民可以继续生产生活活动的区域、形 式、规模、强度和风格, 使社区存续和发展有据可 依; (3)在特许经营、公益岗位、特色产业、生态补 偿等方面，设定有利于社区获益的政策，保障社区 成为国家公园建设的直接受益者; (4)充分尊重原住 民参与国家公园保护的主体权利，明确社区在国家 公园建设运营中组织、决策、管理、服务、监督 等各个环节的参与权利和方式，与社区建立固定协 商机制和共同决策机制, 并用法律形式予以确立。

\section{4 开放授权社会参与生态保护和专业服务}

一方面, 要充分激发全社会共建国家公园热情 
和动能。(1)在生态保护和自然教育方面, 参考国际 上成功的保护地役权方式(魏钰等, 2019), 结合中国 土地产权实际情况, 建议在国家公园部分区域(如集 体林地)试点设置保护权(conservation concession), 使其成为与土地所有权、承包权和经营权之外的 土地分置权利之一, 并通过社区共管、协议保护、 委托保护等方式, 将保护权开放授权给具有保护意 愿和能力的社区、公益组织、企业等社会主体开 展保护和自然教育活动(廖凌云等, 2017; 彭奎, 2020a); (2)通过捐赠减税、绿色债券、公园基金等 机制调动激发社会的资金、技术和人才贡献于国 家公园保护和自然教育等公共服务, 促进保护手段 的多样化和有效性。

另一方面, 要加快构建统一的国家公园特许经 营体系。特许经营作为国家公园最主要的商业服 务形式, 受到各方高度关注(陈朋和张朝枝, 2020; 赵 智聪等, 2020)。特许经营设立标准各异、经营类型 和范围笼统模糊、招标审查不透明、评估监管机 制不健全是目前各试点国家公园的普遍问题。为 了保证特许经营服务国家公园保护的总体目标, 避 免公园价值受到损害, 建议由国家公园管理局制定 统一特许经营管理法规和细则, 并统一(授权)发放 和管理特许经营合同，对特许经营项目类型、范 围、年限、利益分配、社区参与以及合同监督管 理相关内容做出详细规定, 使其既承担为访客提供 必要而适当的公共食宿、基础设施和服务的主要 任务, 又承担起服务全民获得高品质自然体验、认 知和教育的独特使命, 还是地方获取收益的重要渠 道。避免国家公园特许经营沦为商业垄断经营或 成为特殊群体牟利的工具。

\section{5 发展创新的生态服务经济体系}

国家公园作为我国最重要的自然保护地, 是我 国生态文明和美丽中国建设的前沿阵地, 应该成为 解决保护与发展之间矛盾的先行示范区。建议在 国家公园及其周边发展围绕生态系统服务的新型 “经济特区”, 即探索自然保护地生态产品价值的形 成、转化和实现的路径, 发展以保障人类生态安全 为目标、维护和提高生态系统服务功能产出价值 的生态服务型经济体系(葛剑平和孙晓鹏, 2012; 仇 焕广等, 2020)。其核心是将生态系统服务功能价值 融入到社会的主流价值体系中, 用人类普遍遵循的
价值规律来引导和影响全社会的保护与发展活动, 使国家公园管理运行及当地经济发展能获得持续 的、新的经济支持和保障(彭奎, 2020b)。发展国家 公园生态服务经济，以政府为主体将生态补偿机制 变成生态服务型经济的政策激励机制; 构建以社 区、社会企业、社会组织和科研机构组成的生态 服务型经济支持系统; 促进生态服务型经济体系与 主流的市场经济体系链接起来, 使其融入整个社会 的经济体系之中, 实现保护的主流化。

致谢: 本研究得到中国绿色碳汇基金会、祁连山国 家公园青海省管理局和青海省林业和草原局科学 技术与对外合作处等机构支持，张冀强博士、金嘉 满女士、王毅研究员、马克平研究员、王恩光先 生和张莉女士等给予了指导帮助, 在此一并致谢。

\section{参考文献}

Berkes F (2007) Community-based conservation in a globalized world. Proceedings of the National Academy of Sciences, USA, 104, 15188-15193.

Chen P, Zhang CZ (2019) National park concession: International comparison and enlightenment. Journal of Beijing Forestry University (Social Sciences), 18(1), 80-87. (in Chinese with English abstract) [陈朋, 张朝枝 (2019) 国 家公园的特许经营: 国际比较与借鉴. 北京林业大学学报 (社会科学版), 18(1), 80-87.]

Gao Y, Deng Y, Zhang H, Wang JY, Liang B (2017) Community conflicts of the National Park overseas: Performance, tracing origins and enlightenment. Tourism Tribune, 32(1), 111-122. (in Chinese with English abstract) [高燕, 邓毅, 张浩, 王建英, 梁滨 (2017) 境外国家公园社 区管理冲突: 表现、溯源及启示. 旅游学刊, 32(1), 111-122.]

Garnett ST, Burgess ND, Fa JE, Fernández-Llamazares Á, Molnár Z, Robinson CJ, Watson JEM, Zander KK, Austin B, Brondizio ES, Collier NF, Duncan T, Ellis E, Geyle H, Jackson MV, Jonas H, Malmer P, McGowan B, Sivongxay A, Leiper I (2018) A spatial overview of the global importance of Indigenous lands for conservation. Nature Sustainability, 1, 369-374.

Ge JP, Sun XP (2012) The theory and practice of economy in eco-service type. Journal of Xinjiang Normal University (Edition of Philosophy and Social Sciences), 33(4), 7-15, 118. (in Chinese with English abstract) [葛剑平, 孙晓鹏 (2012) 生态服务型经济的理论与实践. 新疆师范大学学 报(哲学社会科学版), 33(4), 7-15, 118.]

He SY, Wei Y, Su Y, Min QW (2020) Guaranteeing fair and 
sustainable benefit sharing for communities in the National Park: A study from perception of meanings of socialecological systems. Acta Ecologica Sinica, 40, 2450-2462. (in Chinese with English abstract) [何思源, 魏钰, 苏杨, 闵 庆文 (2020) 保障国家公园体制试点区社区居民利益分享 的公平与可持续性一一基于社会-生态系统意义认知的研 究. 生态学报, 40, 2450-2462.]

Li L, Fassnacht FE, Storch I, Bürgi M (2017) Land-use regime shift triggered the recent degradation of alpine pastures in Nyanpo Yutse of the eastern Qinghai-Tibetan Plateau. Landscape Ecology, 32, 2187-2203.

Liao LY, Zhao ZC, Yang R (2017) Model analysis of community participation in protection of China's protected areas based on a comparative study of six cases. Chinese Landscape Architecture, 33(8), 30-33. (in Chinese with English abstract) [廖凌云, 赵智聪, 杨锐 (2017) 基于 6 个 案例比较研究的中国自然保护地社区参与保护模式解析. 中国园林, 33(8), 30-33.]

Peng K (2020a) Community conservation concession agreement: From Sanjiangyuan experience to global vision. Sanjiangyuan Ecology, 24(2), 32-35. (in Chinese) [彭奎 (2020a) 社区协议保护: 从三江源实践到全球视野. 三江源 生态, 24(2), 32-35.]

Peng K (2020b) From conservation agreement to ecosystem service based economy: Approaching method of ecological value realization. China Environment, 76(7), 26-31 (in Chinese with English abstract) [彭奎 (2020b) 从协议保护 到生态服务型经济: 自然生态价值实现的路径探索. 中华 环境, 76(7), 26-31.]

Qiu HG, Zhang YT, Peng K (2020) The development of ecological service-oriented economy: Theory, model and practice. Reform, (8), 18-29. (in Chinese with English abstract) [仇焕广, 张神娅, 彭奎 (2020) 生态服务型经济发 展: 理论、模式与实践. 改革, (8), 18-29.]

Rai ND, Devy MS, Ganesh T, Ganesan R, Setty SR, Hiremath
AJ, Khaling S, Rajan PD (2021) Beyond fortress conservation: The long-term integration of natural and social science research for an inclusive conservation practice in India. Biological Conservation, 254, 108888.

Wei Y, He SY, Lei GC, Su Y (2019) Establishing conservation easement system to promote unified management of China's national parks: US-based experience. Journal of Beijing Forestry University (Social Sciences), 18(1), 70-79. (in Chinese with English abstract) [魏钰, 何思源, 雷光春, 苏杨 (2019) 保护地役权对中国国家公园统一管理的启示基于美国经验. 北京林业大学学报(社会科学版), 18(1), 70-79.]

Xu WG, Gao J, Xia X, Zhou DQ, Li ZL, Jiang MK (2016) Distribution of community residents in nature reserves and its impacts on the reserves in China. Journal of Ecology and Rural Environment, 32, 19-23. (in Chinese with English abstract) [徐网谷, 高军, 夏欣, 周大庆, 李中林, 蒋明康 (2016) 中国自然保护区社区居民分布现状及其影响. 生 态与农村环境学报, 32, 19-23.]

Zang ZH, Zhang D, Wang N, Du A, Kong LQ, Xu WH, Ouyang ZY (2020) Experiences, achievement, problems and recommendations of the first batch of China's national park system pilots. Acta Ecologica Sinica, 40, 8839-8850. (in Chinese with English abstract) [㶓振华, 张多, 王楠, 杜傲, 孔令桥, 徐卫华, 欧阳志云 (2020) 中国首批国家公园体制 试点的经验与成效、问题与建议. 生态学报, 40, 8839-8850.]

Zhao ZC, Wang P, Xu C (2020) Concession management of the US National Park system and its enlightenment. Environmental Protection, 48(8), 70-75. (in Chinese) [赵智 聪, 王沛, 许婵 (2020) 美国国家公园系统特许经营管理及 其启示. 环境保护, 48(8), 70-75.]

(责任编委: 徐卫华 责任编辑: 周玉荣) 